Supporting Information

\title{
Electrochemical Cyclobutane Synthesis in Flow: Scale-up of a Promising Melt-Castable Energetic Intermediate
}

Longrui Chen,$^{\dagger}$ Lisa M. Barton, ${ }^{\dagger}$ Julien C. Vantourout, ${ }^{\dagger}$ Yinghua Xu,, Chengpu Chu, $\S^{\S}$ Eric C. Johnson, $¥$ Jesse J. Sabatini, ${ }^{,} \neq$and Phil S. Baran*,†

†Department of Chemistry, Scripps Research, 10550 North Torrey Pines Road, La Jolla, California 92037

₹CCDC US Army Research Laboratory, Energetics Synthesis \& Formulation Branch, Aberdeen Proving Ground, MD 21005

§College of Chemical Engineering, Zhejiang University of Technology, Hangzhou, China 310032 


\section{Table of Contents}

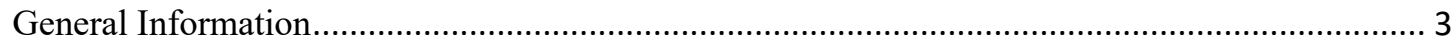

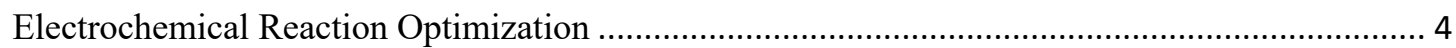

Batch Reactor Setup

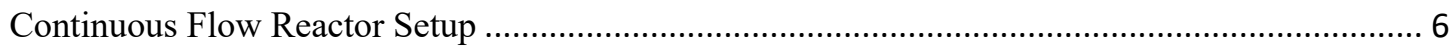

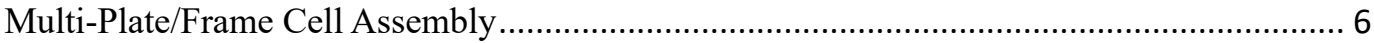

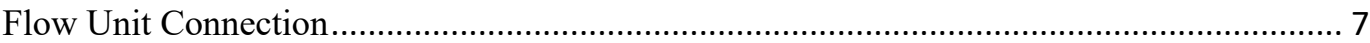

Graphical Information for Nitration and Recrystallization .................................................... 11

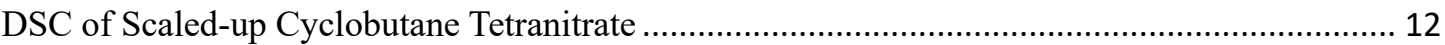

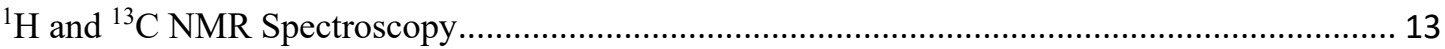

Compound 8

Compound 5

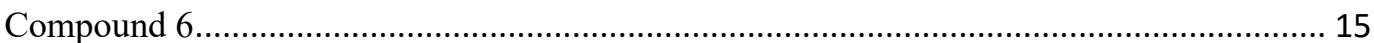

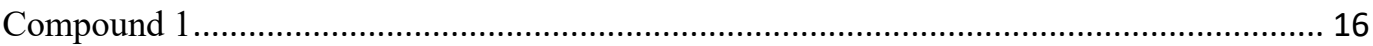

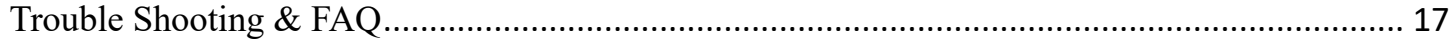

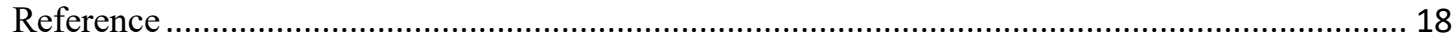




\section{General Information}

$N, N$-dimethylformamide (DMF), toluene, and methanol ( $\mathrm{MeOH})$ were obtained by passing the previously degassed solvents through an activated alumina column. Reagents were purchased at the highest commercial quality grade and used without further purification, unless otherwise stated. An ElectroSyn 2.0 was used for batch reactions and was purchased from IKA. Continuous flow system reactor and its components were purchased from Hangzhou Saiao Electrochemical Technology Co. Ltd, China. Yields refer to chromatographically and spectroscopically ( ${ }^{1} \mathrm{H}$ NMR) homogeneous material, unless otherwise stated. The reactions were monitored by GC/MS, ${ }^{1} \mathrm{H}$ NMR, and thin layer chromatography (TLC). TLC was performed using $0.25 \mathrm{~mm}$ E. Merck Silica plates (60F-254), using short-wave UV light as the visualizing agent, acidic ethanolic anisaldehyde, or $\mathrm{KMnO}_{4}$ and heat as developing agents. NMR spectra were recorded on Bruker DRX-600 and Bruker $400 \mathrm{MHz}$ Avance III HD Magnet instruments and are calibrated using residual undeuterated solvent $\left(\mathrm{CHCl}_{3}\right.$ at $7.26 \mathrm{ppm}{ }^{1} \mathrm{H}$ NMR, $77.16 \mathrm{ppm}{ }^{13} \mathrm{C}$ NMR; acetone- $\mathrm{d}_{6}$ at $2.05 \mathrm{ppm}{ }^{1} \mathrm{H}$ NMR, $29.84 \mathrm{ppm}{ }^{13} \mathrm{C}$ NMR). The following abbreviations were used to explain multiplicities: $\mathrm{s}=$ singlet, $\mathrm{d}=$ doublet, $\mathrm{t}=$ triplet, $\mathrm{q}$ $=$ quartet $\mathrm{m}=$ multiplet, $\mathrm{br}=$ broad. Column chromatography was performed using E. Merck Silica (60, particle size 0.043-0.063 mm). High-resolution mass spectra (HRMS) were recorded on an Agilent LC/MSD TOF mass spectrometer by electrospray ionization time of flight reflectron experiments. Melting points were recorded on a Fisher-Johns 12-144 melting point apparatus and are uncorrected. Infrared spectra were measured with a Bruker Alpha-P FTIR instrument. Melting and decomposition temperatures of tetranitrates were measured at a heating rate of $5{ }^{\circ} \mathrm{C} / \mathrm{min}$ using a TA Instruments Q10 DSC instrument. 


\section{Electrochemical Reaction Optimization}

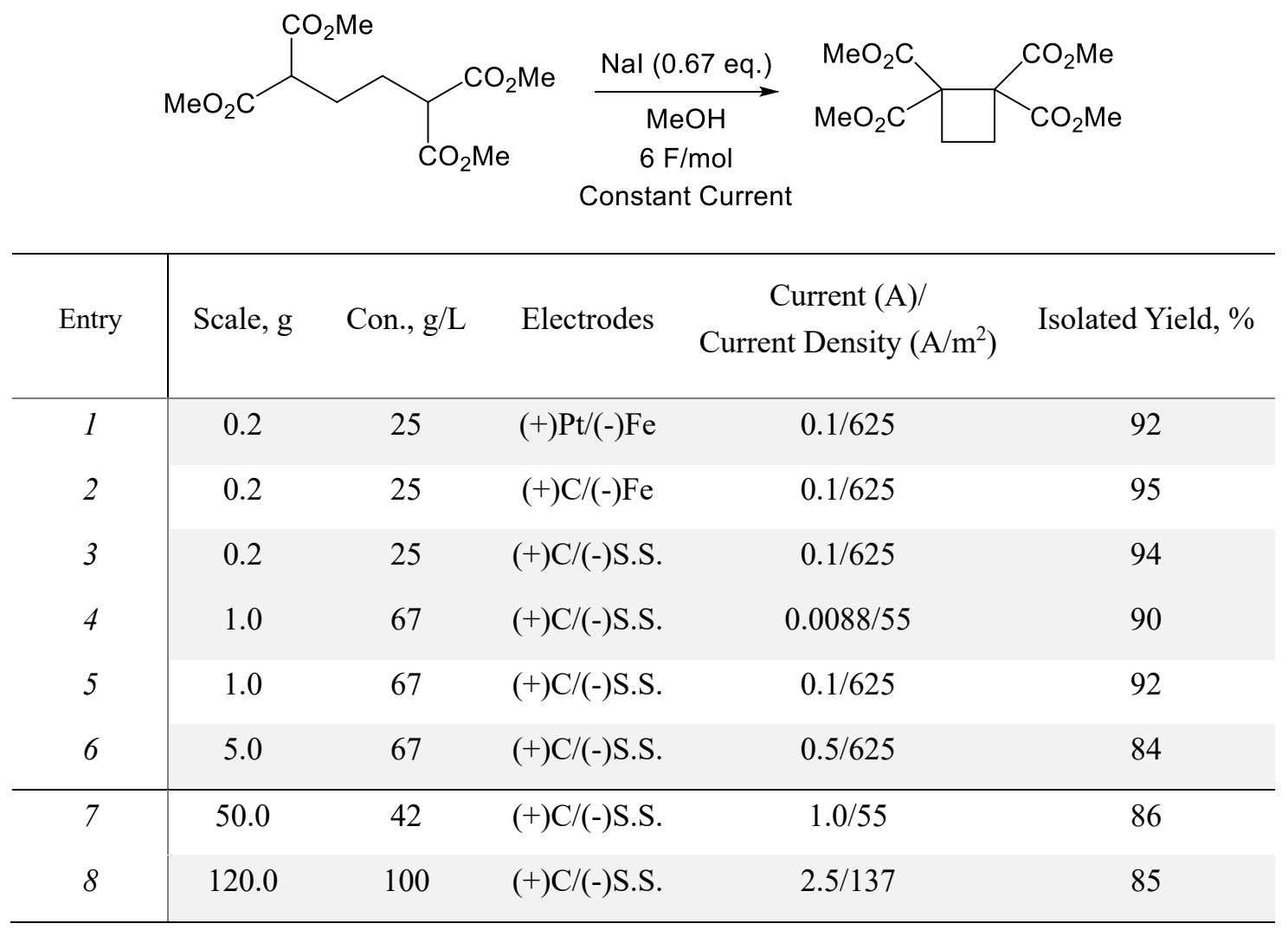

Table S1: entry 1-6 conducted in batch reactor ${ }^{1}$, entry $7-8$ conducted in flow reactor. 


\section{Batch Reactor Setup}

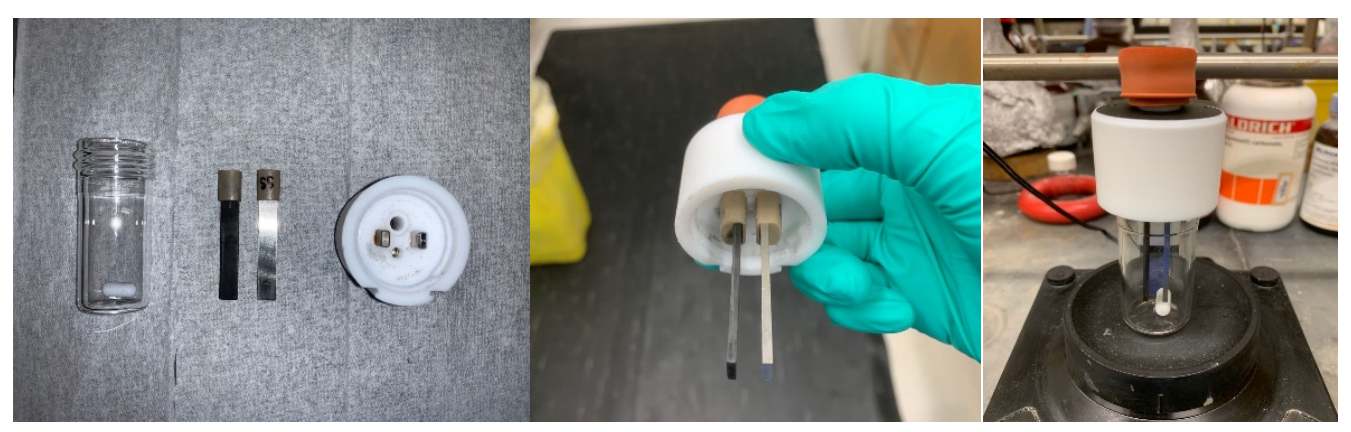

Figure S1. Setup A (ElectraSyn 2.0): (Left) Vial, electrodes, cap. (Center) Assembled ElectraSyn cap with graphite anode and stainless steel cathode. (Right) Assembly on ElectraSyn 2.0 .
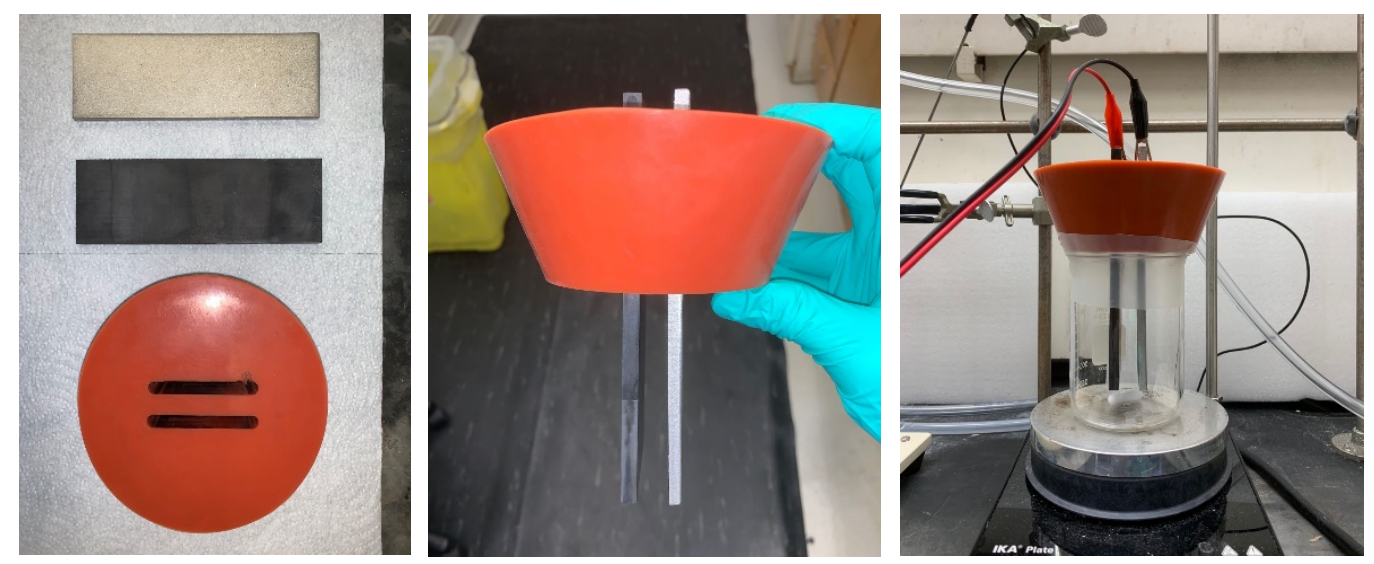

Figure S2. Setup B (Homemade batch reactor): (Left) Stainless steel cathode, graphite anode, cap. (Center) Assembled cap with graphite anode and stainless steel cathode. (Right) Assembled batch reactor. 


\section{Continuous Flow Reactor Setup}

Multi-Plate/Frame Cell Assembly: The components for the setup of an individual cell include: 8 cap screws (made from 304 stainless steel, length: $10.8 \mathrm{~cm}$ ), 2 stainless steel pressure plates, 2 bakelite plates (insulating plate), 4 fluororubber gaskets (with a space of $13 \mathrm{~cm} \times 7 \mathrm{~cm} \times 0.2 \mathrm{~cm}$ ), 2 PTFE frames (with a channel size of $13 \mathrm{~cm} \times 7 \mathrm{~cm} \times 2 \mathrm{~cm}$ ), 2 stainless steel cathodes and 1 graphite anode. The two PTFE frames are placed between the graphite anode plate and stainless steel cathode plate. Four fluororubber gaskets are inserted between each electrode plate and PTFE frame. Two bakelite plates are placed outside of cathodes with two stainless steel pressure plates, then all plates and frames were threaded through and fastened by 8 cap screws to finish cell assembly. The total volume of cell is $365 \mathrm{~mL}$.

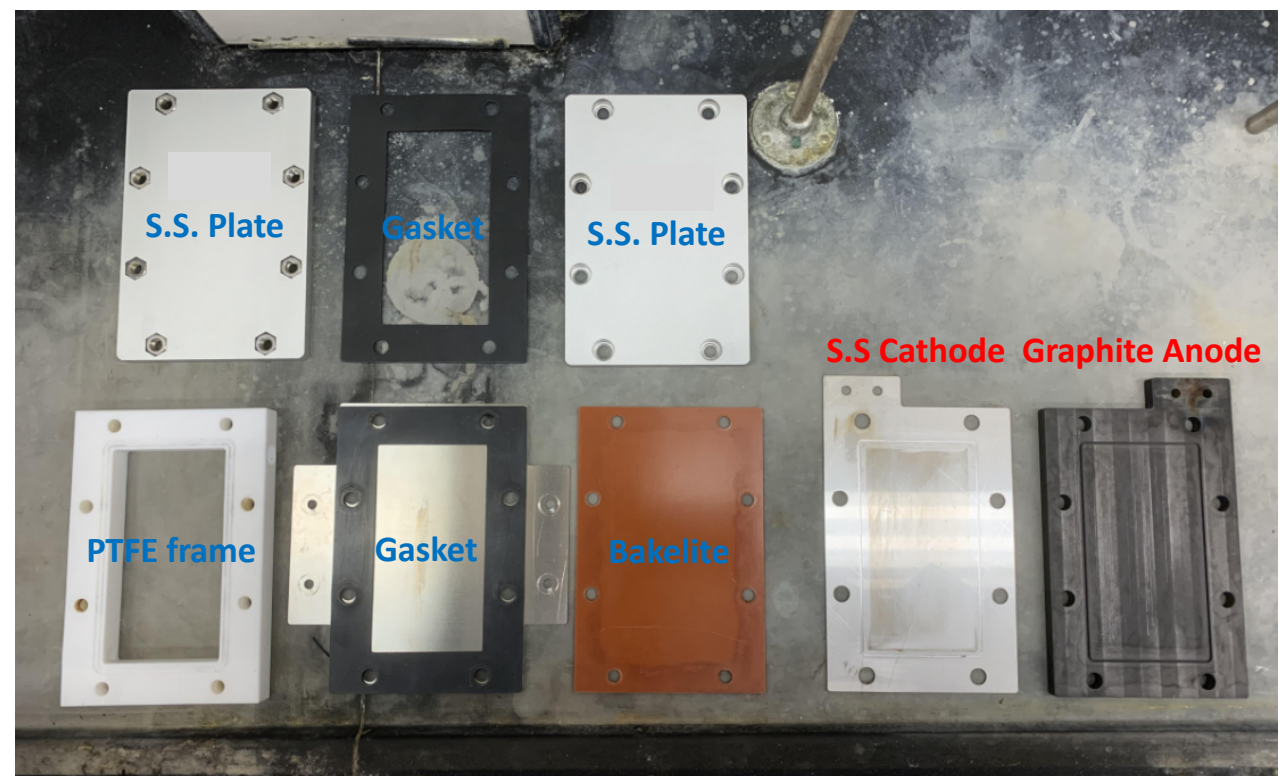

Figure S3. Components of multi-plate/frame cell: Stainless Steel Plate, Gasket, Bakelite, PTFE frame, Stainless Steel Cathode, Graphite Anode. 


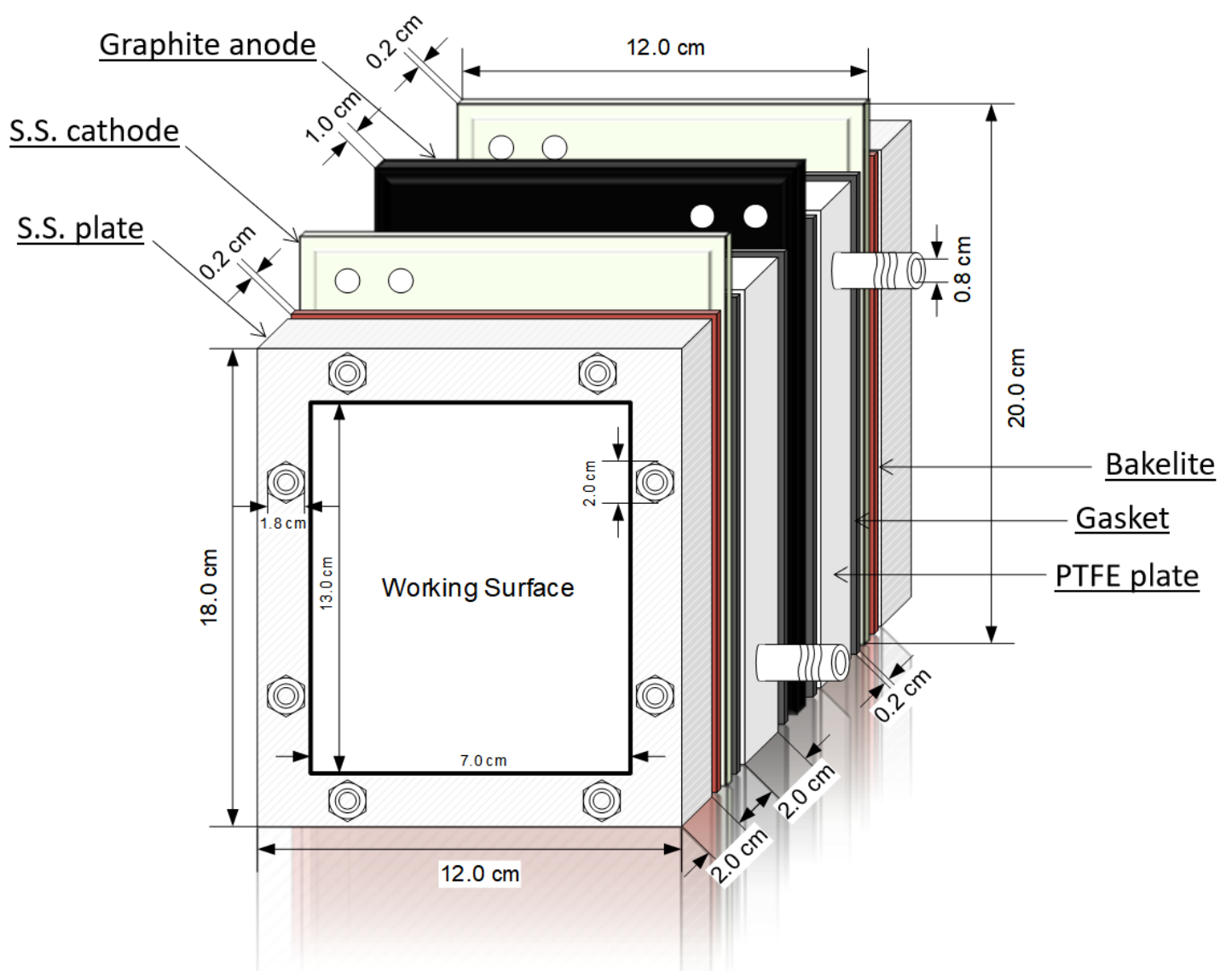

Figure S4. Measurement of assembled multi-plate/frame cell

Flow Unit Connection: The assembled cell was connected, by fluororubber tube (3/8" ID, 5/8" OD), to a magnetic circulating pump and a $1.0 \mathrm{~L}$ jacketed glass reservoir. A flow meter (measuring range from $16 \mathrm{~L} / \mathrm{h}$ to $160 \mathrm{~L} / \mathrm{h}$ ) was placed between the assembled cell and pump. The Teflon barbed fittings on the side of PTFE frames were connected via fluororubber tube to the fitting on the adjacent PTFE frame to allow the solution to flow between each cell. One of the two end fittings connects to the pump, as the inlet of flow transferring reaction solution from reservoir to the cell; another fitting was connected directly to the reservoir, as the outlet of flow moving solution from the cell back to the reservoir and thus forming a closed flow loop. The reservoir can be placed under argon if necessary. The anode plate is connected through a wire to the positive terminal of a direct current power supply (maximum 5.0 A, 60.0 V), while the corresponding cathode plates are connected to the negative terminal. 

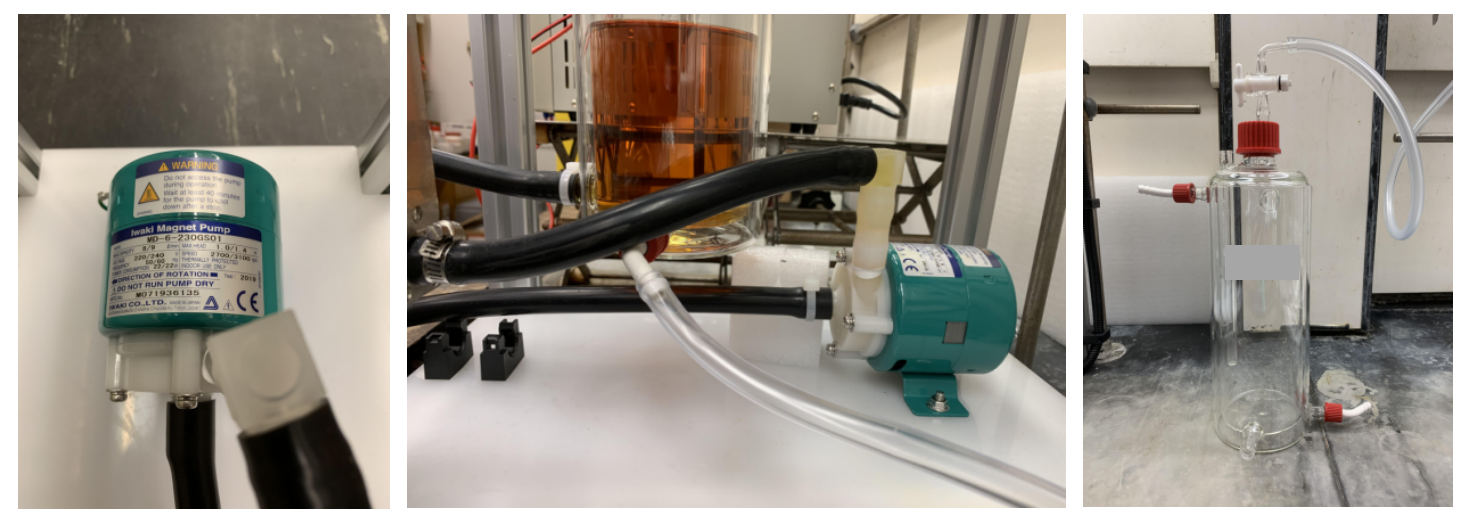

Figure S5. (Left) Circulating Pump (Center) Pump in a running reaction (Right) 1.0 L jacketed reservoir
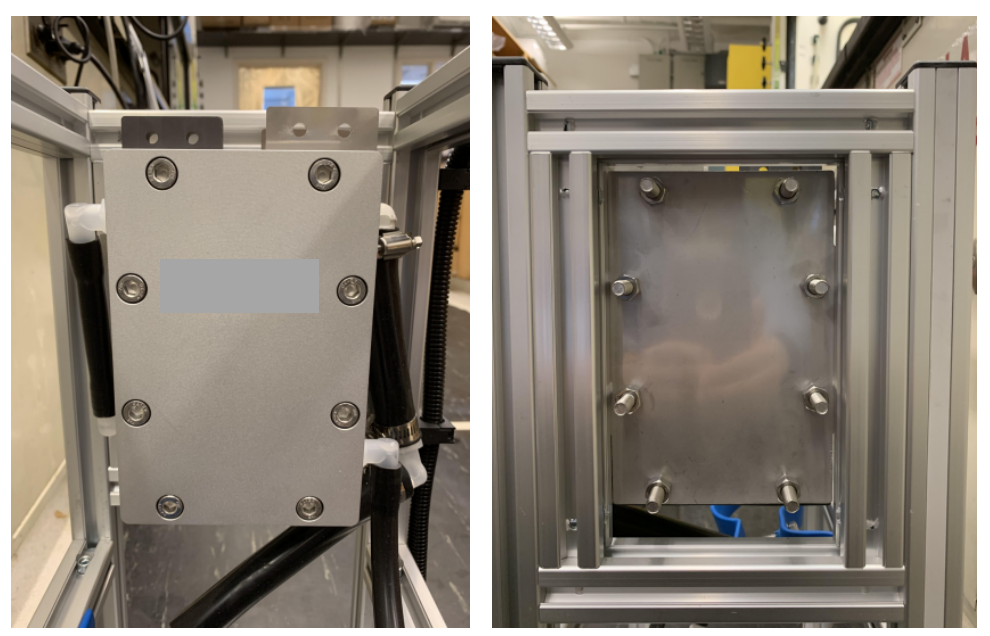

Figure S6. (Left) Front view of fixed multi-plate/frame cell in continuous flow system reactor. (Right) Back view of fixed multi-plate/frame cell in continuous flow system reactor. 

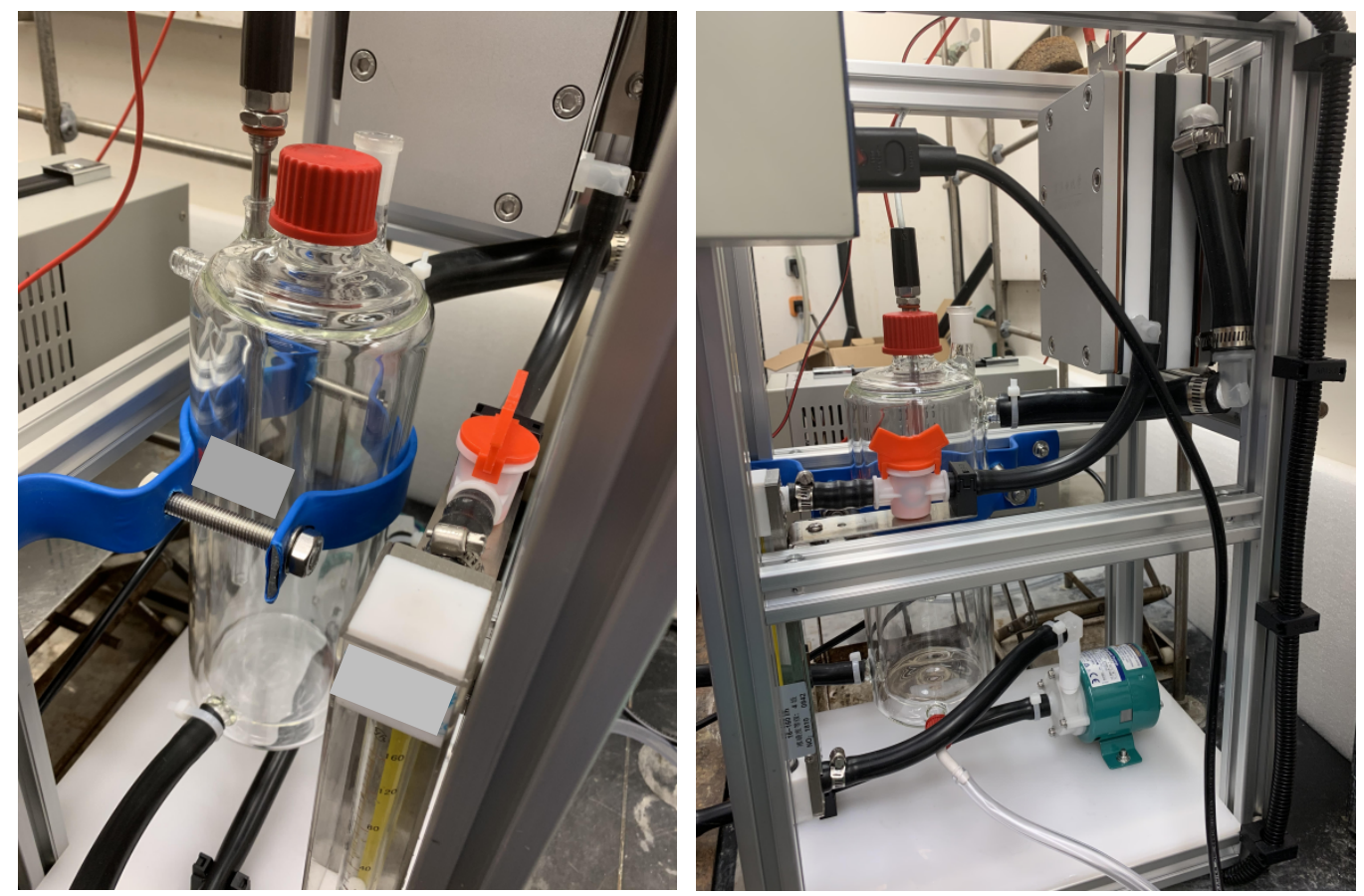

Figure S7. (Left) Fix reservoir in flow reactor. (Right) Side view of assembled continuous flow reactor.
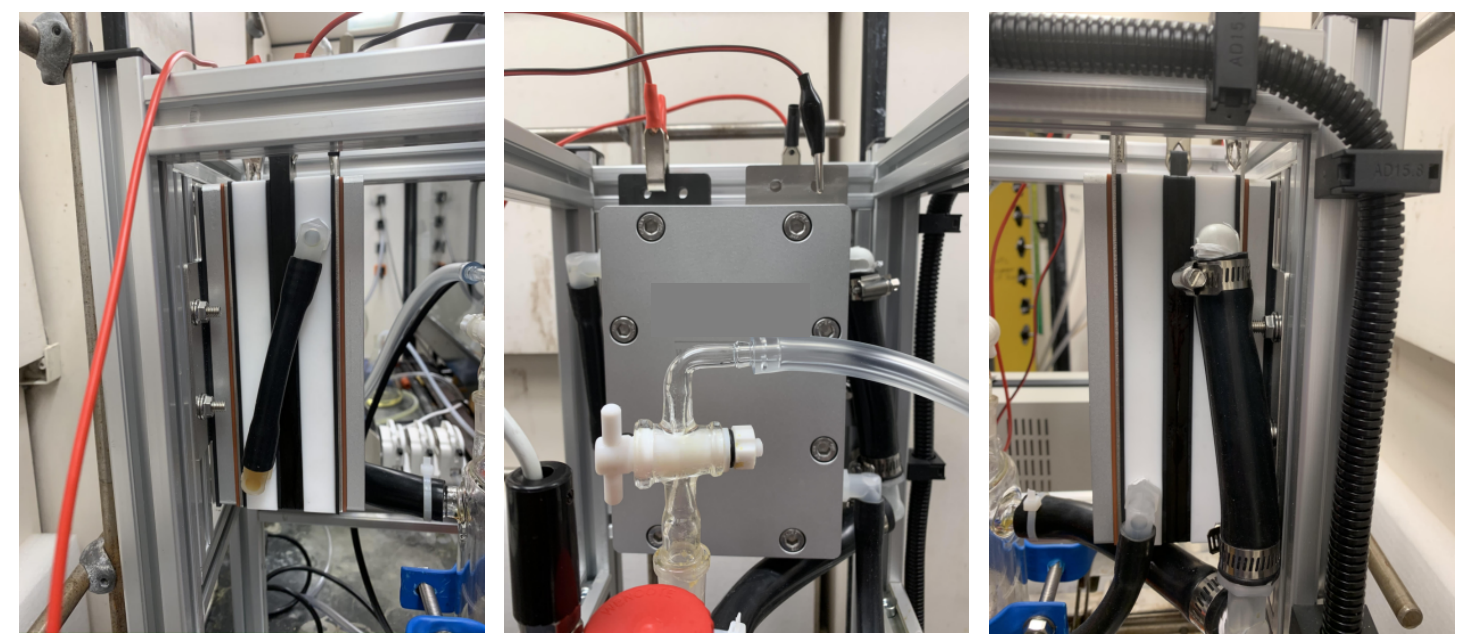

Figure S8. (Left) Left view of multi-plate/frame cell of running flow reactor. (Center) Front view of multi-plate/frame cell of running flow reactor. (Right) Right view of multi-plate/frame cell of running flow reactor. 


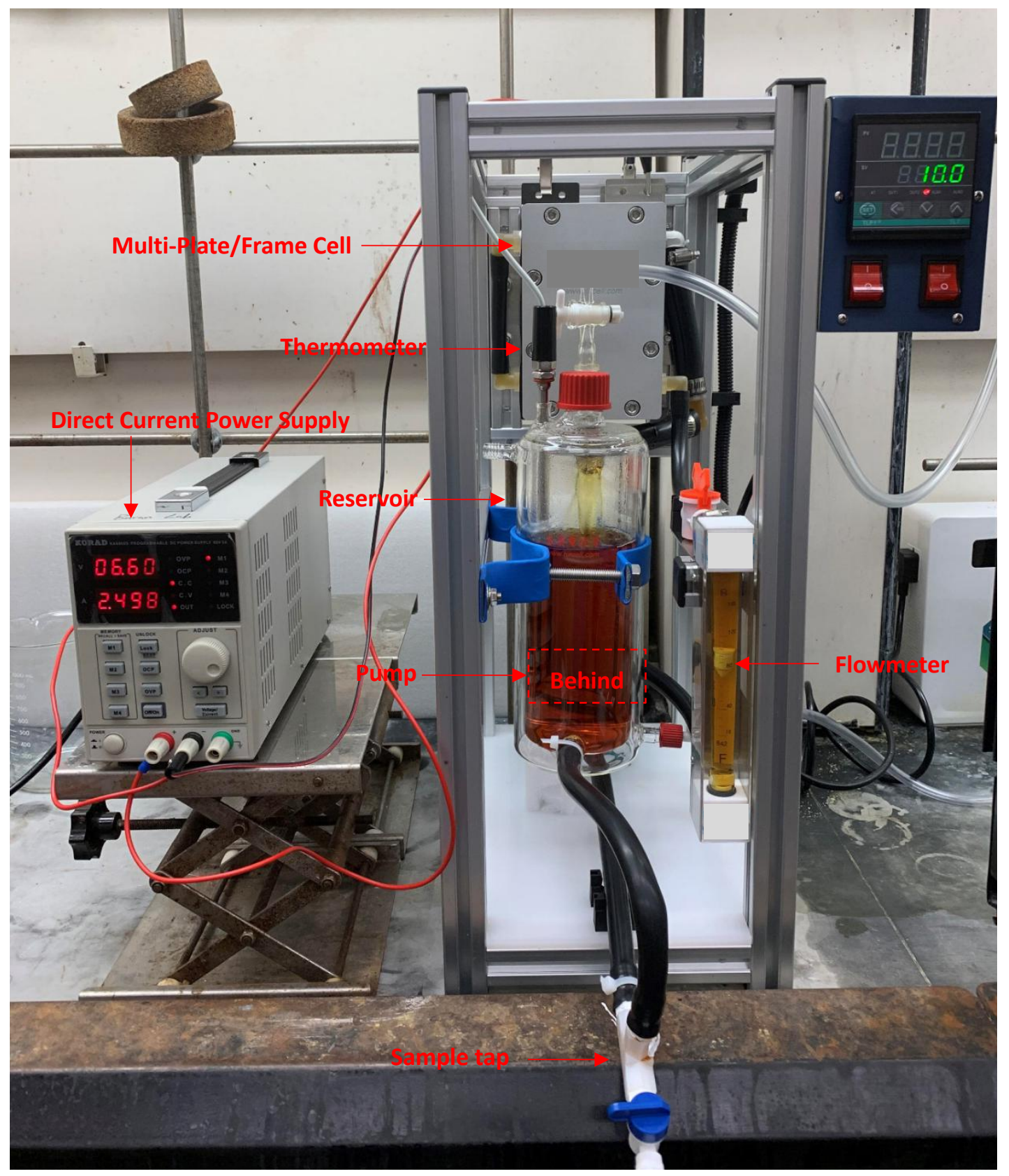

Figure S9. Reaction in continuous flow reactor (Preparation of compound 6, $120 \mathrm{~g}$ scale). 


\section{Graphical Information for Nitration and Recrystallization}
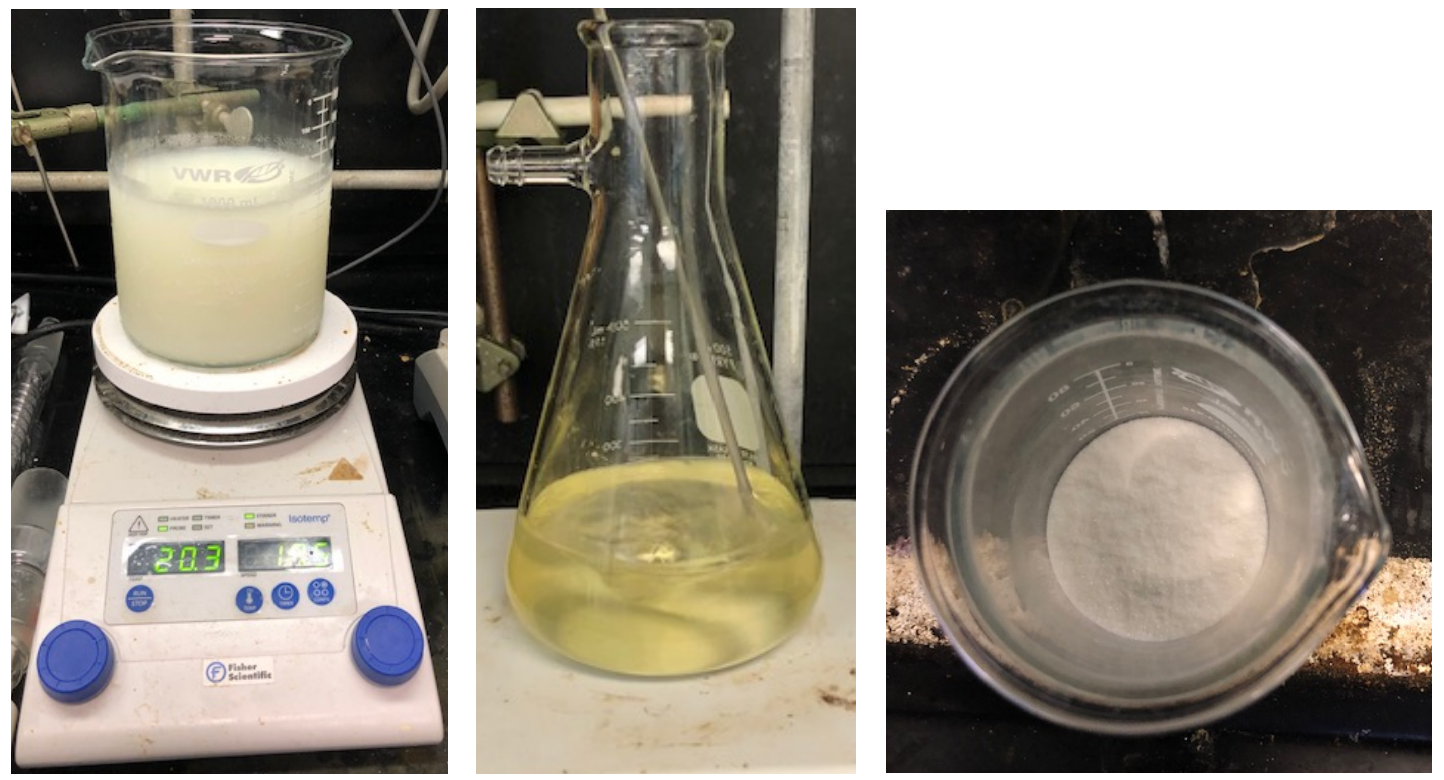

Figure S10. (Left) Quenching of nitration after pouring the reaction over crushed ice. (Middle) Recrystallization of solid from iPrOH. (Right) Pure compound 1 after recrystallization, filtration and drying. 


\section{DSC of Scaled-up Cyclobutane Tetranitrate}

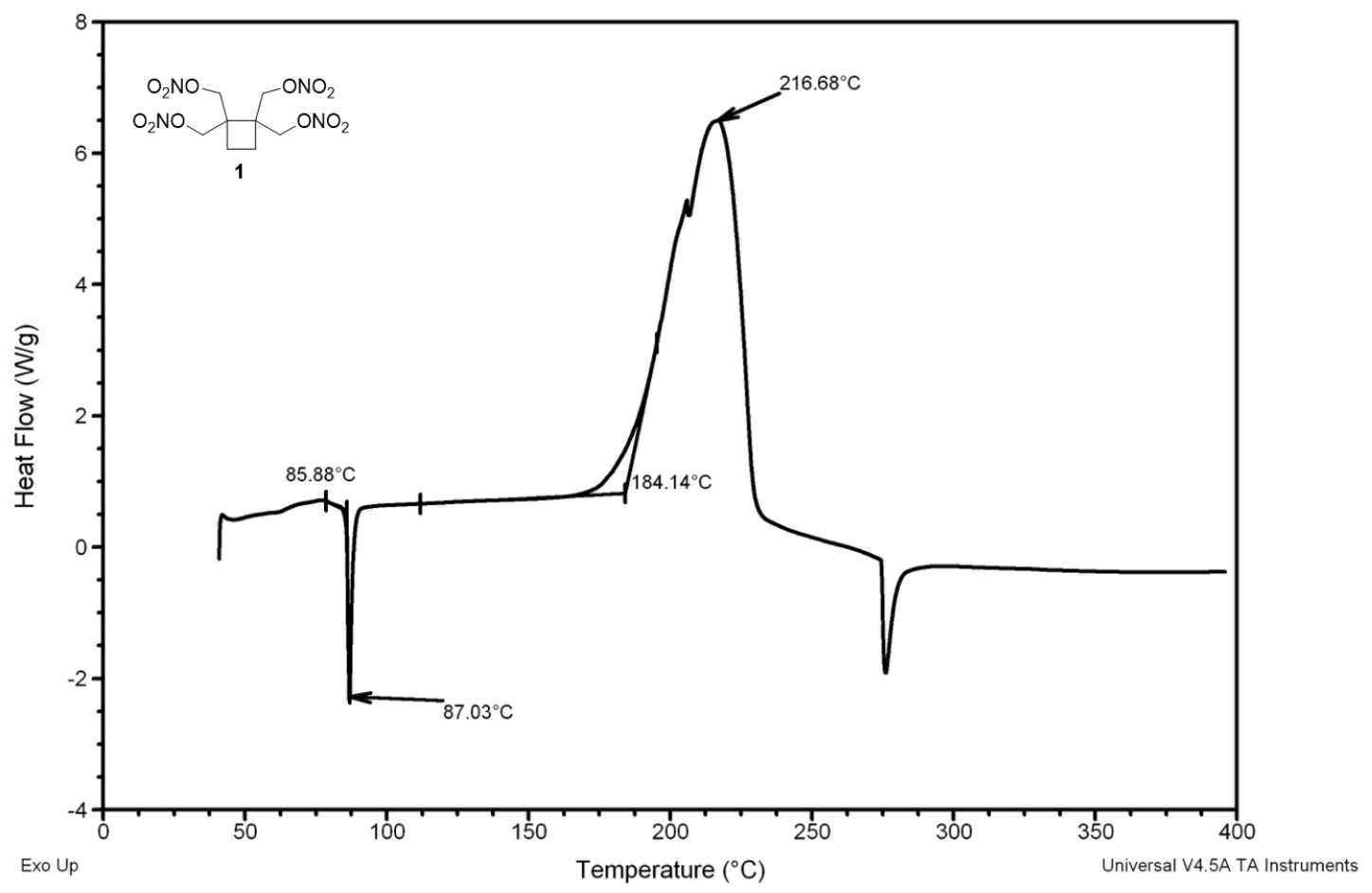




\section{${ }^{1} \mathrm{H}$ and ${ }^{13} \mathrm{C}$ NMR Spectroscopy}

\section{Compound $8{ }^{1} \mathrm{H}$ NMR}

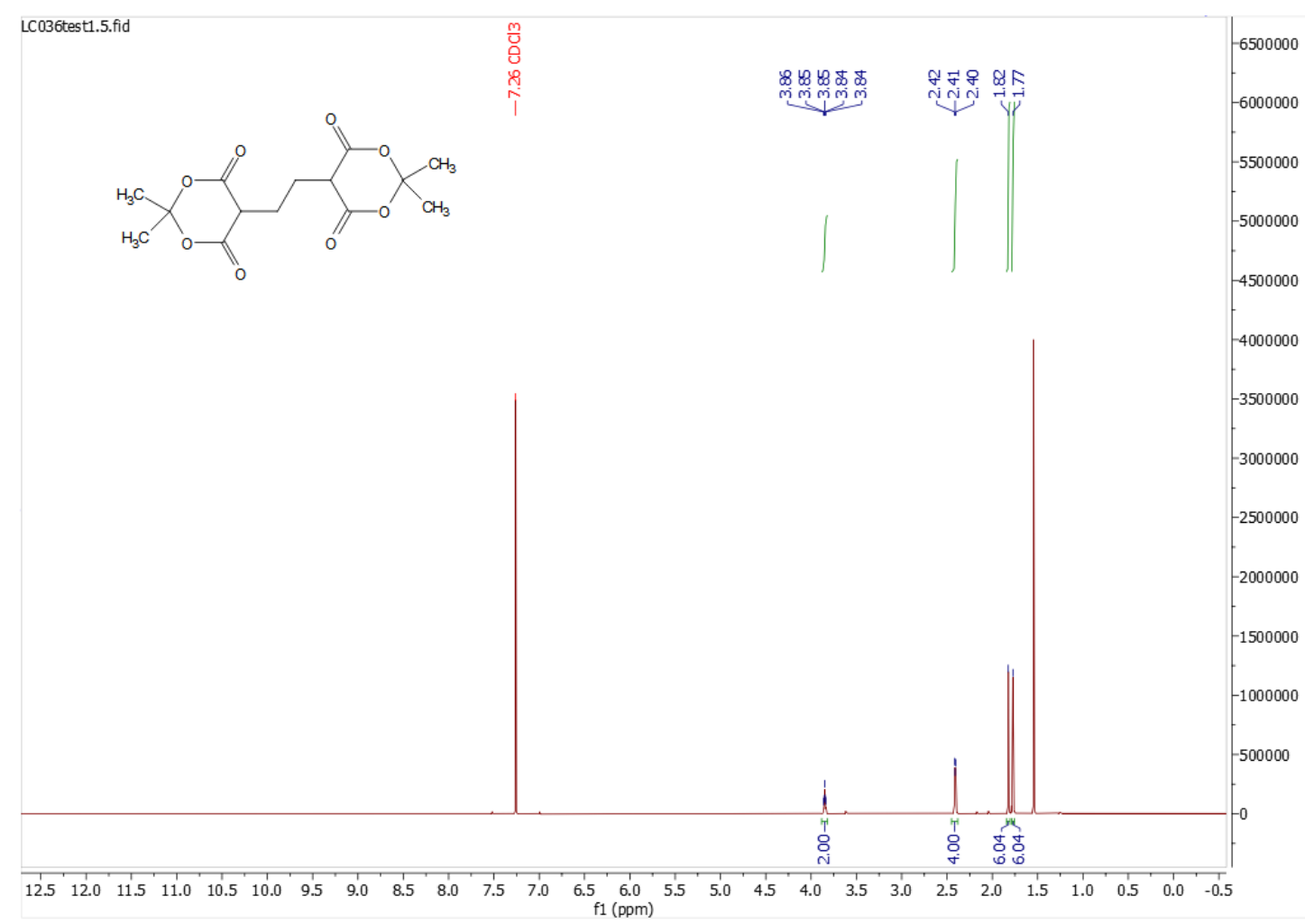

\section{Compound $8{ }^{13} \mathrm{C}$ NMR}

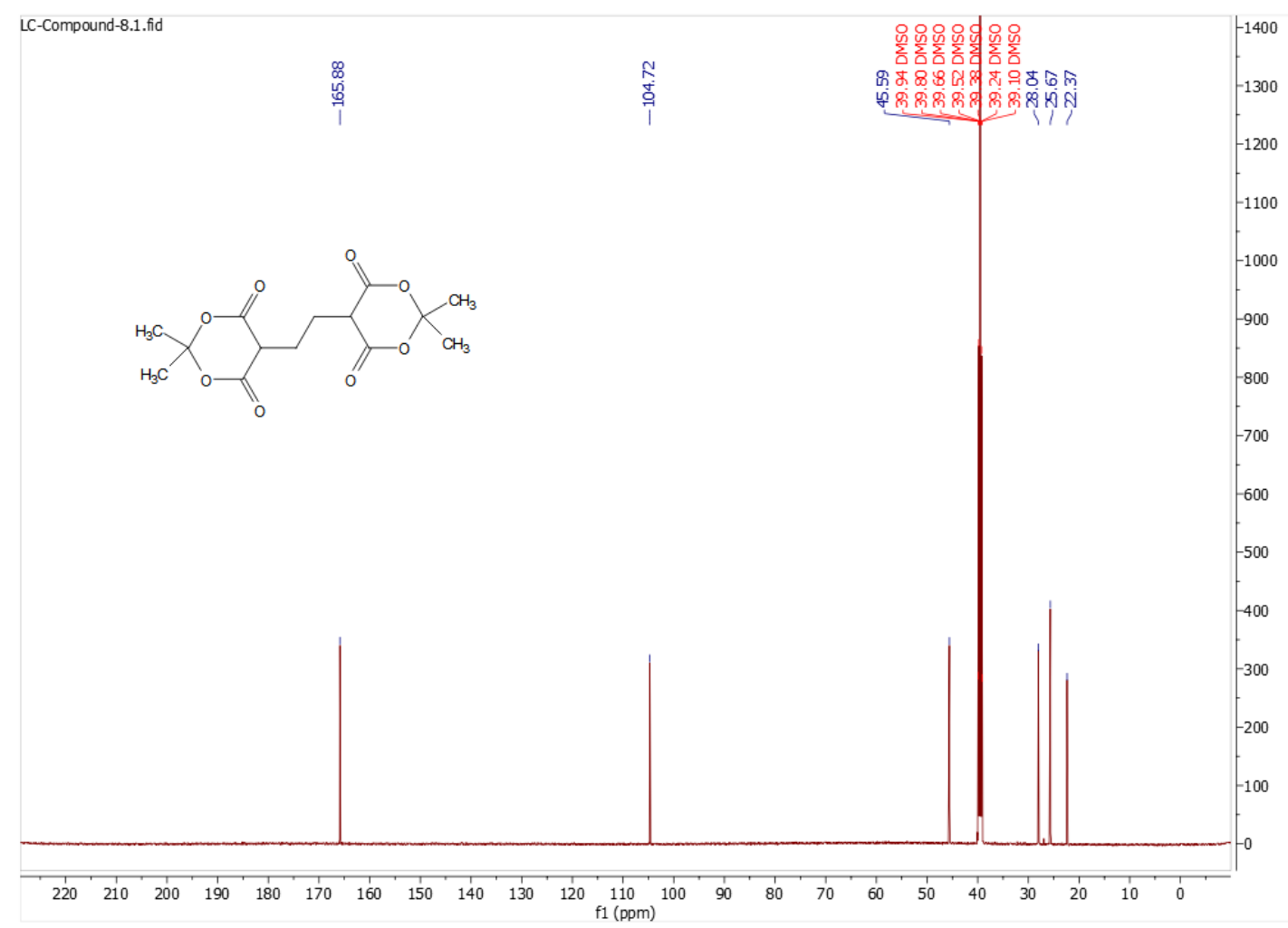




\section{Compound $5{ }^{1} \mathrm{H}$ NMR}

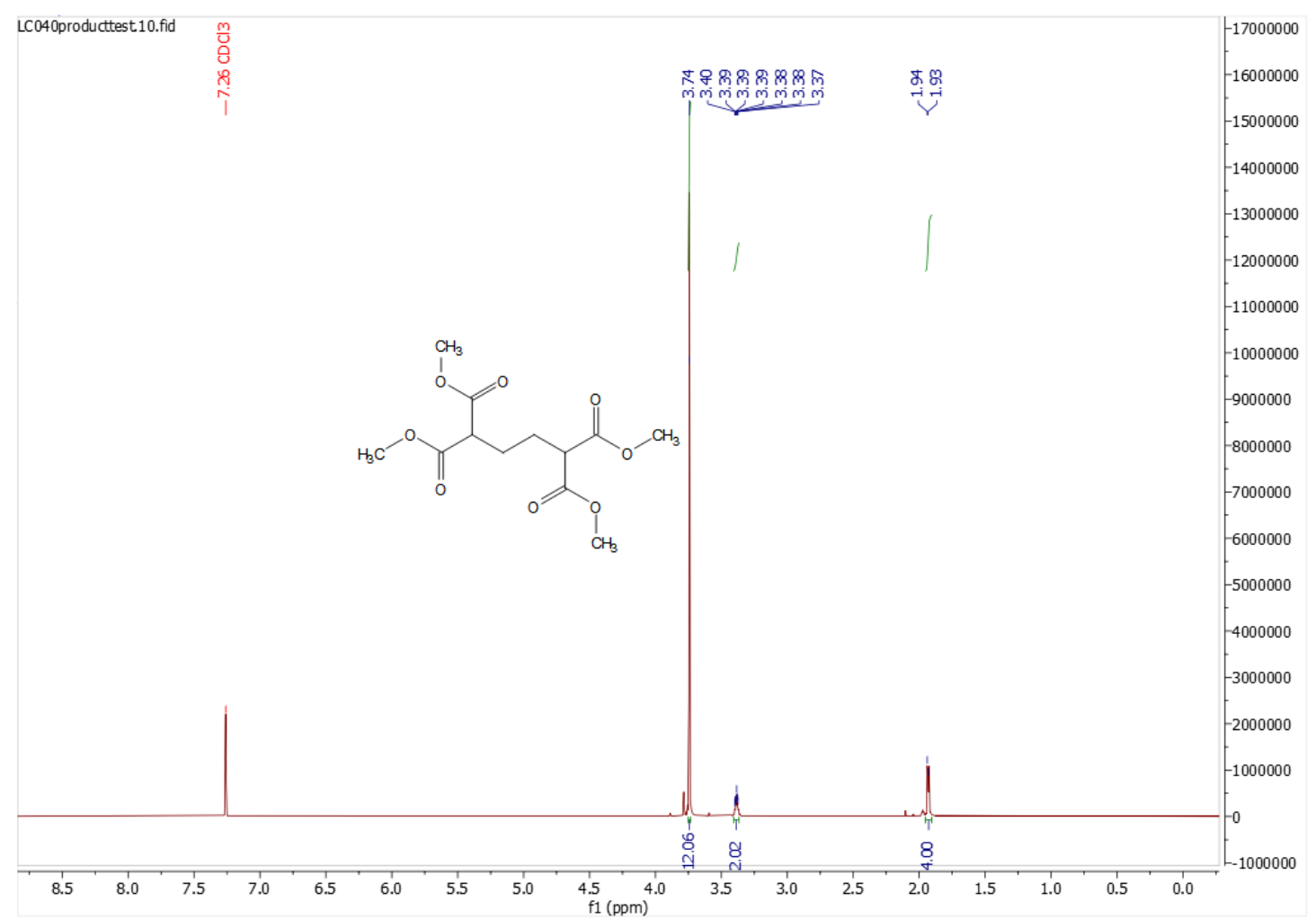

\section{Compound $5{ }^{13} \mathrm{C}$ NMR}

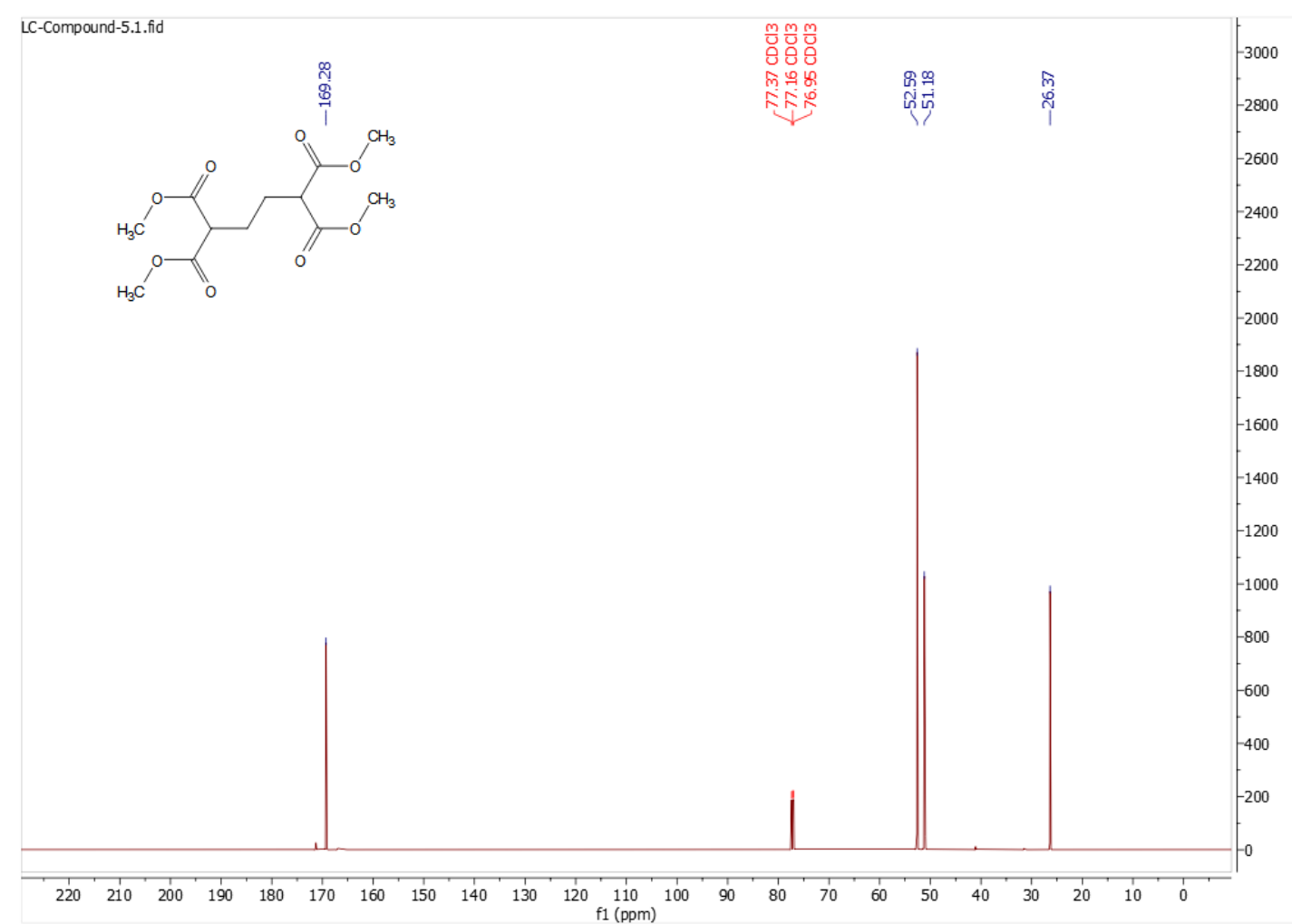


Compound $6{ }^{1} \mathrm{H}$ NMR

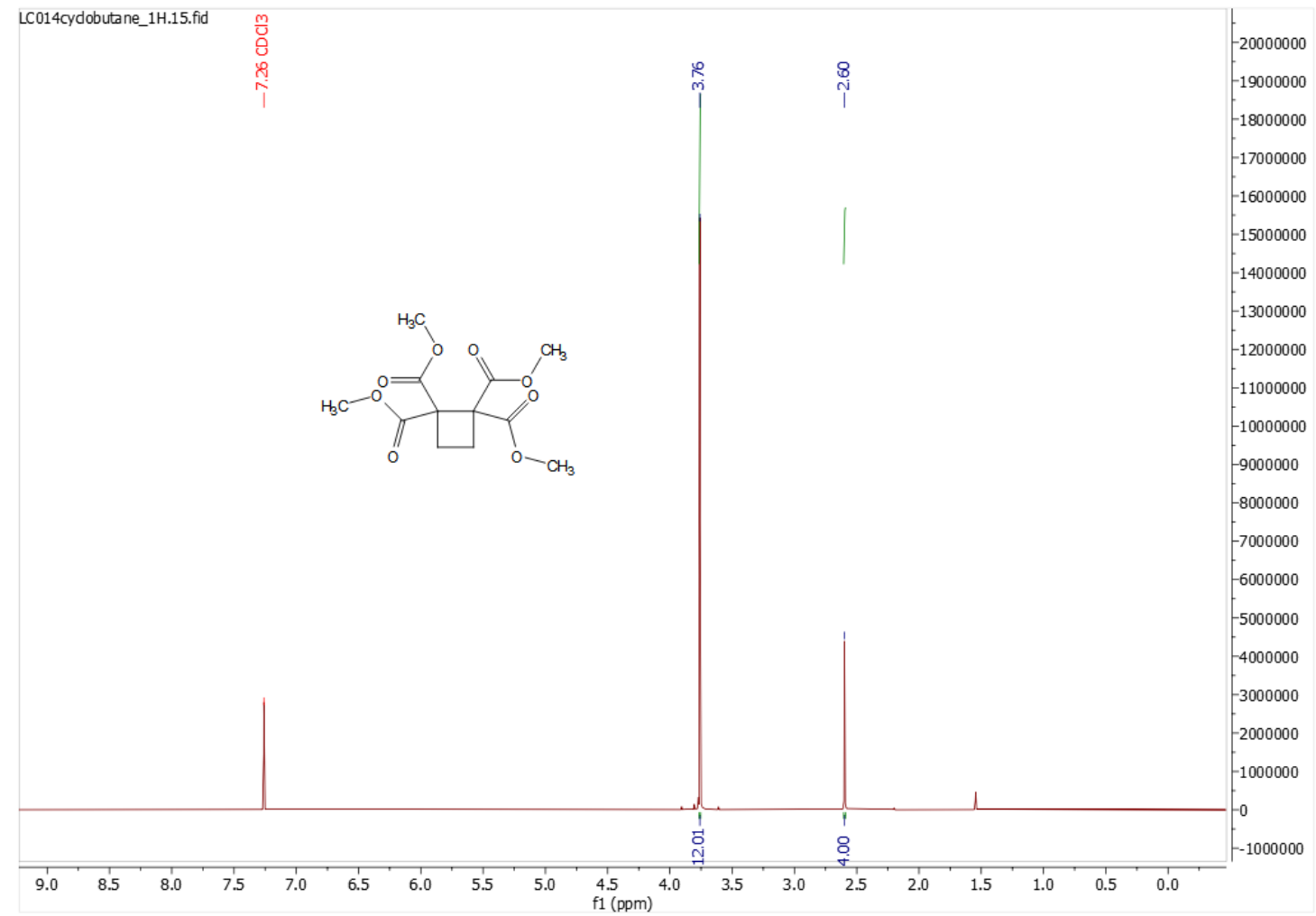

Compound $6{ }^{13} \mathrm{C}$ NMR

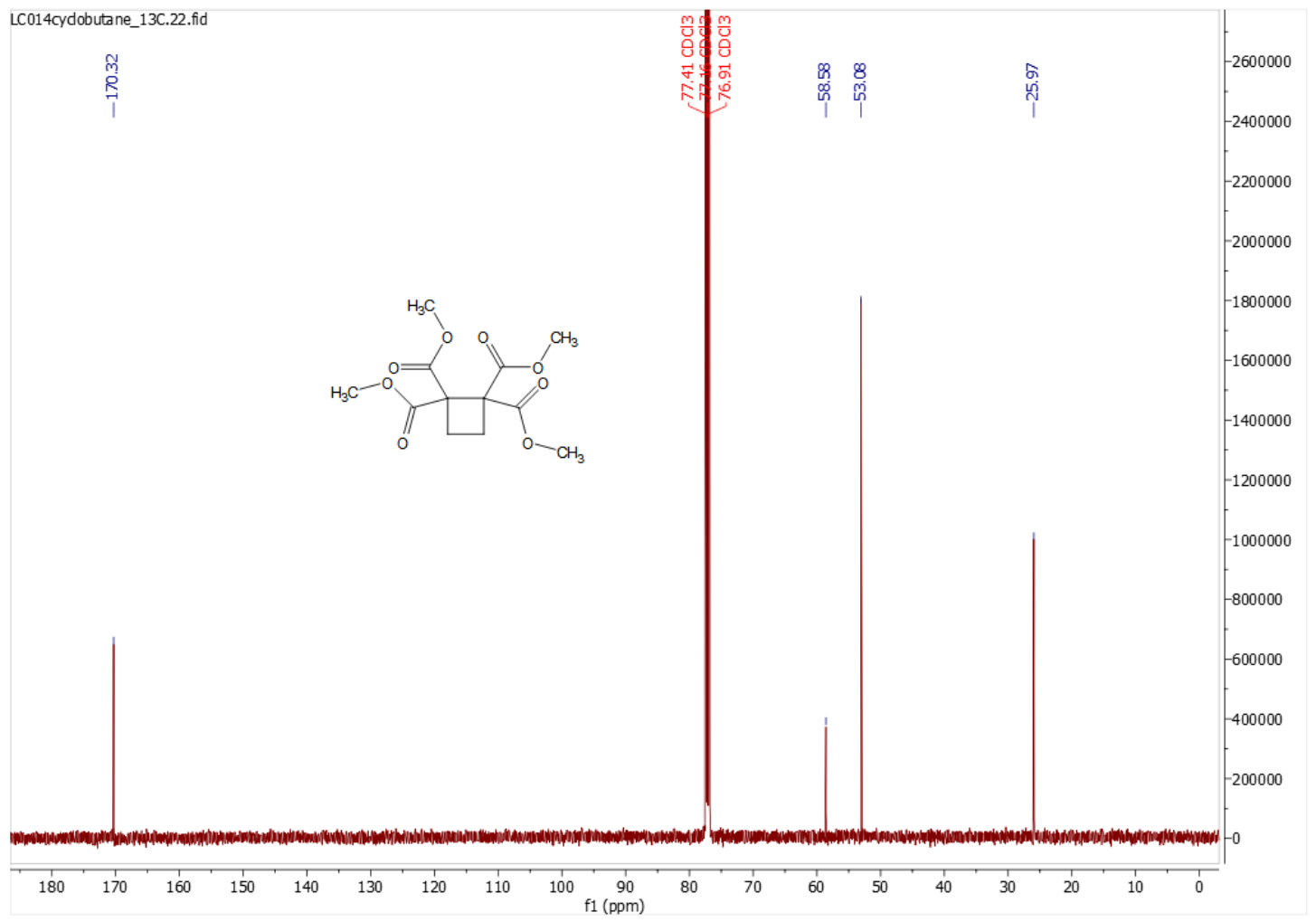

15 


\section{Compound $1{ }^{1}$ H NMR}

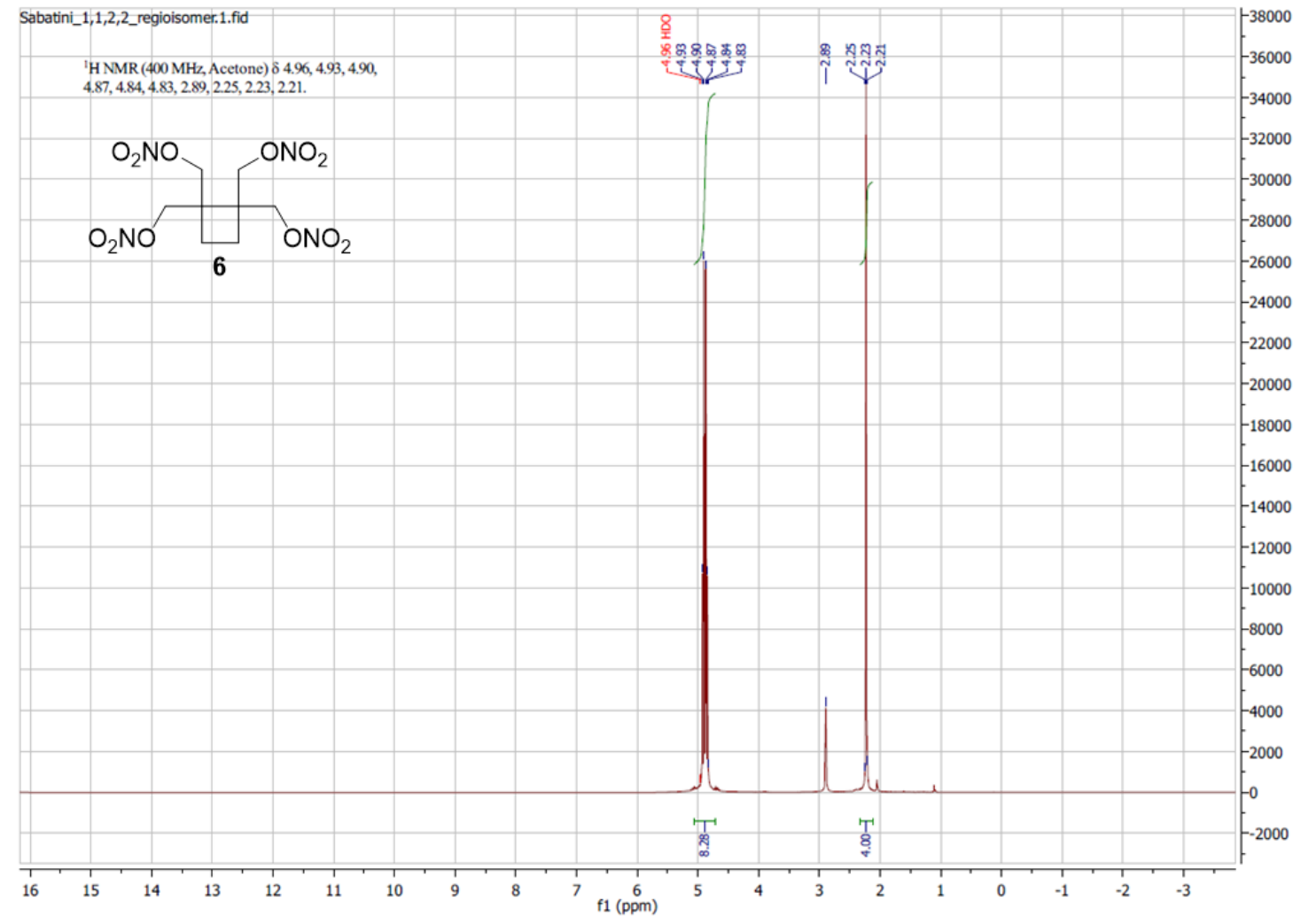

\section{Compound $1{ }^{13} \mathrm{C}$ NMR}

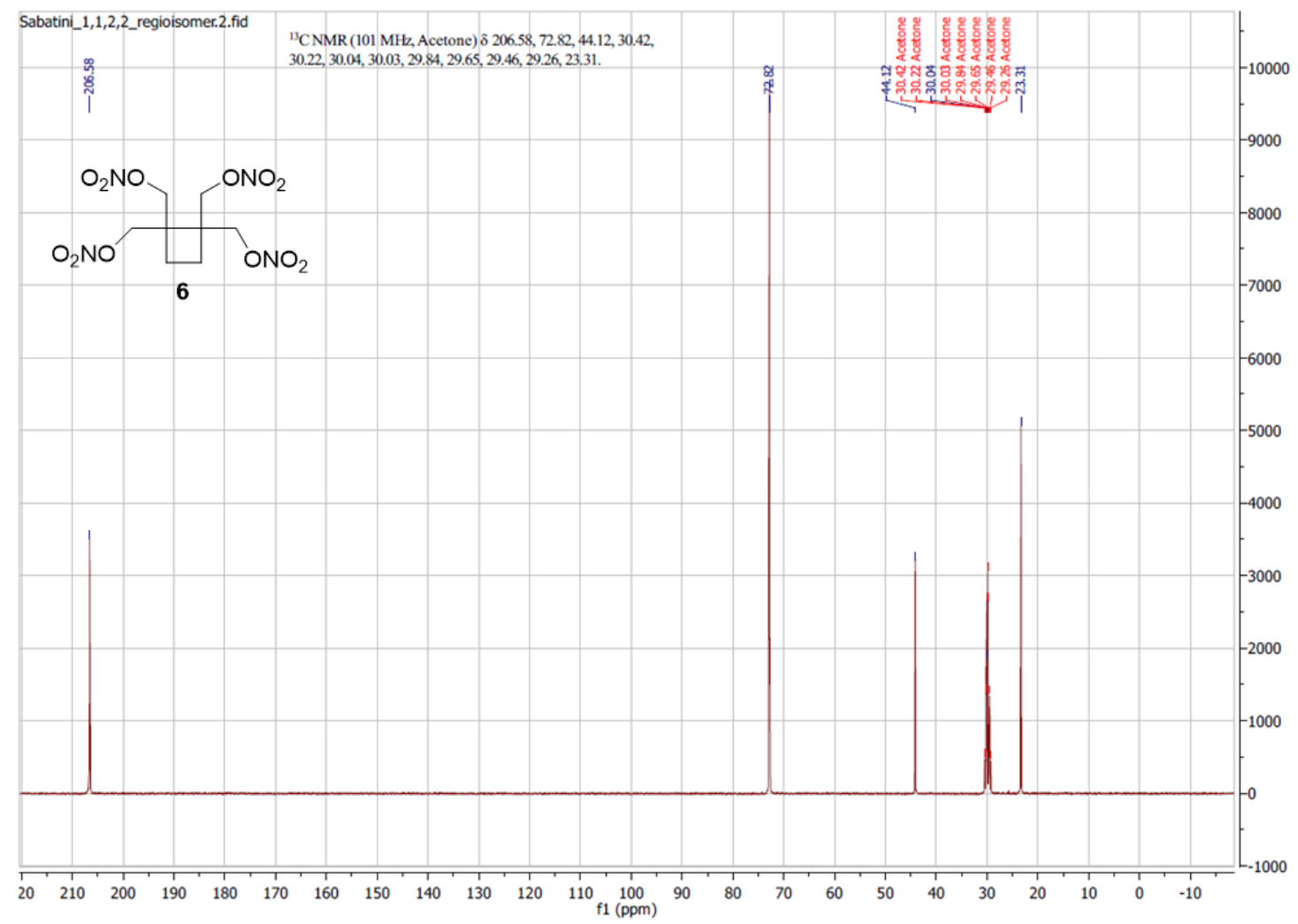




\section{Trouble Shooting \& FAQ}

Q: Can this flow reactor use other materials as electrodes?

A: Yes, the electrodes can easily be replaced and other metals such as aluminum, zinc, magnesium, etc. can act as electrodes in this continuous flow reactor for many other reactions.

Q: Does the continuous flow reactor provide a stable flow rate during electrolysis?

A: Yes, the flow rate of this system is very stable and can be adjusted from $16 \mathrm{~L} / \mathrm{h}$ to $160 \mathrm{~L} / \mathrm{h}$.

Q: Does this flow reactor work for a reaction that involves a sacrificial anode?

A: Yes, it works. We have a successful example using a similar flow reactor for an electrochemical birch reaction which involves magnesium as sacrificial anode. ${ }^{2}$

Q: Does this flow reactor tolerate corrosive environment such as an acidic or basic condition?

A: Yes, it does. All materials used for making this flow reactor including tubing system, fittings plates/frames are corrosive resistant.

Q: How do you control the temperature of the reaction in this flow reactor?

A: The jacketed reservoir can fill with water/cooling fluid and connect to external cooler to keep the reaction in a controllable temperature range, increase the flow rate can also help remove the heat generated on the electrodes. 


\section{Reference}

(1) Barton, L. M.; Edwards, J. T.; Johnson, E. C.; Bukowski, E. J.; Sausa, R. C.; Byrd, E. F. C.; Orlicki, J. A.; Sabatini, J. J.; Baran, P. S. Impact of Stereo- And Regiochemistry on Energetic Materials. J. Am. Chem. Soc. 2019, 141, 12531-12535.

(2) Peters, B. K.; Rodriguez, K. X.; Reisberg, S. H.; Beil, S. B.; Hickey, D. P.; Kawamata, Y.; Collins, M.; Starr, J.; Chen, L.; Udyavara, S.; Klunder, K.; Gorey, T. J.; Anderson, S. L.; Neurock, M.; Minteer, S. D.; Baran, P. S. Scalable and Safe Synthetic Organic Electroreduction Inspired by Li-Ion Battery Chemistry. Science 2019, 363, 838-845. 